
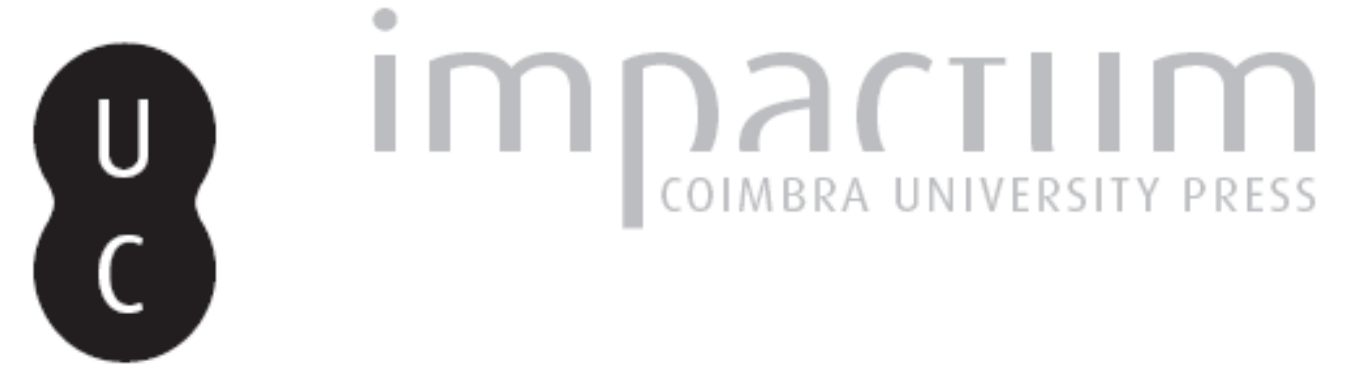

\title{
A geografia da Lousã no período das Invasões Francesas
}

\section{Autor(es): $\quad$ Carvalho, Paulo de}
Publicado por: Faculdade de Letras da Universidade de Coimbra, Departamento de Geografia

URL persistente:

URI:http://hdl.handle.net/10316.2/30189

DOI:

DOI:http://dx.doi.org/10.14195/0871-1623_31_3

Accessed : $\quad$ 26-Apr-2023 16:29:03

A navegação consulta e descarregamento dos títulos inseridos nas Bibliotecas Digitais UC Digitalis, UC Pombalina e UC Impactum, pressupõem a aceitação plena e sem reservas dos Termos e Condições de Uso destas Bibliotecas Digitais, disponíveis em https://digitalis.uc.pt/pt-pt/termos.

Conforme exposto nos referidos Termos e Condições de Uso, o descarregamento de títulos de acesso restrito requer uma licença válida de autorização devendo o utilizador aceder ao(s) documento(s) a partir de um endereço de IP da instituição detentora da supramencionada licença.

Ao utilizador é apenas permitido o descarregamento para uso pessoal, pelo que o emprego do(s) título(s) descarregado(s) para outro fim, designadamente comercial, carece de autorização do respetivo autor ou editor da obra.

Na medida em que todas as obras da UC Digitalis se encontram protegidas pelo Código do Direito de Autor e Direitos Conexos e demais legislação aplicável, toda a cópia, parcial ou total, deste documento, nos casos em que é legalmente admitida, deverá conter ou fazer-se acompanhar por este aviso.

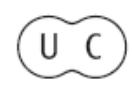




\section{A geografia da Lousã no período das Invasões Francesas}

\section{Paulo de Carvalho}

Departamento de Geografia e Centro de Estudos de Geografia e Ordenamento do Território (CEGOT). Faculdade de Letras da Universidade de Coimbra. paulo.carvalho@fl.uc.pt

\section{Nota Preliminar}

O presente texto resulta da comunicação com o mesmo título apresentada no dia 18 de março de 2011 no âmbito das III Jornadas "As Invasões Francesas e a Península Ibérica: Comemoração do Bicentenário da $3^{\text {a }}$ Invasão - O Combate de Foz de Arouce: Impactos e Memórias Locais" (Figura 1).

Este evento, organizado pela Câmara Municipal da Lousã em colaboração com o Departamento de História da Faculdade de Letras da Universidade de Coimbra e a Comissão Coordenadora do Exército para as Comemorações dos 200 anos da Guerra Peninsular (e com diversos outros apoios), contou com a participação de

\section{Bicentenário das Invasões Francesas}

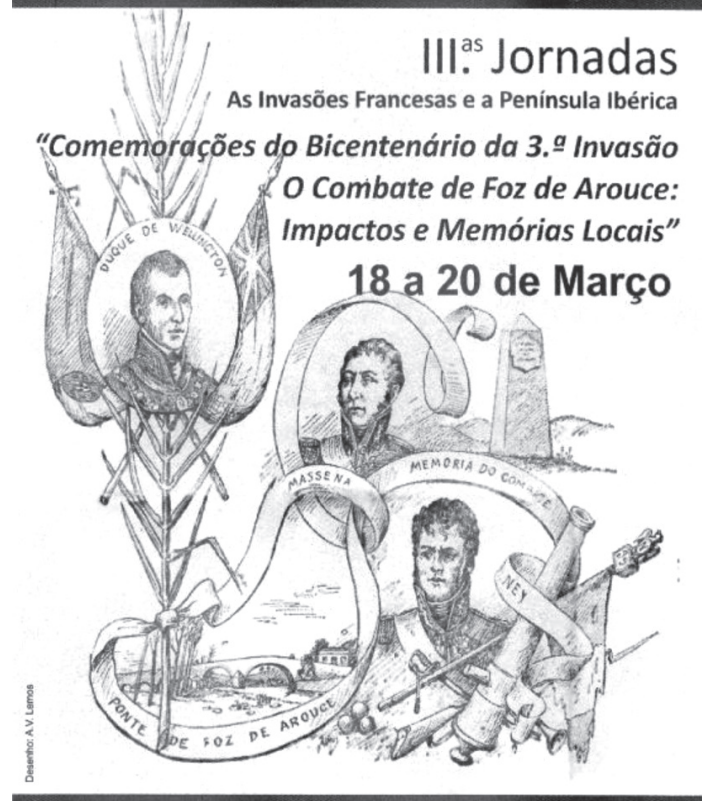

Figura 1

Folheto das III Jornadas "As Invasões Francesas e a Península Ibérica"; o desenho evocativo do Combate de Foz de Arouce é da autoria de Álvaro Viana de Lemos e foi publicado no jornal "Commercio da Louzã" $\left(n^{\circ} 73\right.$, 15/03/1911) por ocasião do $1^{\circ}$ centenário desta batalha

Fonte: Câmara Municipal da Lousã (2011) investigadores e especialistas nacionais, e teve o melhor acolhimento da parte do público interessado que encheu por completo o Auditório da Biblioteca Municipal da Lousã.

De forma paralela, decorreu a exposição "O Terreno, o Engenho e a Arte de fortificar pararam a Invasão de Massena", ocorreu o lançamento de uma edição especial de vinho "Quinta de Foz de Arouce" alusiva a esta temática e o lançamento da obra "O Combate de Foz de Arouce (1811): Evocação Histórica" da autoria de Ana Filipa Rodrigues Sêco.

O programa contemplou ainda atividades como a recriação de acampamento militar da época, a recriação da Batalha de Foz de Arouce (março de 1811 Figura 2), a cerimónia militar (homenagem póstuma) aos mortos em batalha e descerramento de placa comemorativa no obelisco (do centenário) junto à ponte de Foz de Arouce, o desfile de uma marcha popular e a inauguração do mirante da batalha, todas com larga participação de público nos dias 18 a 20 de março de 2011.

A minha proposta de reflexão pretendeu contribuir para uma leitura geográfica da Lousã no alvor do século XIX. Tempo de transição, muito marcado pelos episódios das Invasões Francesas, o início de Oitocentos é um pretexto para (re)ler as fontes mais relevantes da

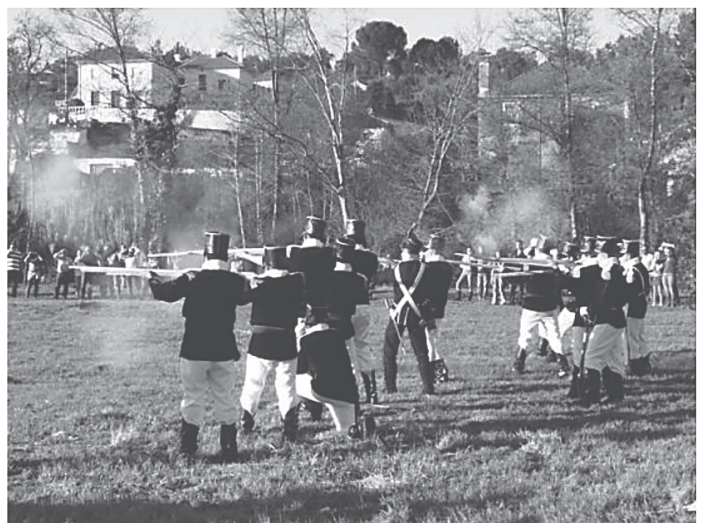

Figura 2

Recriação histórica do Combate de Foz de Arouce, junto à ponte sobre o rio Ceira $(20 / 03 / 2011)$ 
geografia histórica local, regional e nacional, no sentido de explicitar as configurações e dinâmicas territoriais que marcaram a Lousã (e o seu quadro geográfico de relação) nesse período.

Assumindo como principal preocupação, a ocupação e a organização espacial da Lousã, através de escalas (de espaço e tempo) recorrentes e articuláveis, as linhas estruturantes desta intervenção configuram quatro eixos temáticos, a saber: o enquadramento geográfico; as vias de comunicação; a população e o povoamento; e o espaço urbano da Lousã.

\section{Diversidade Paisagística}

A diversidade paisagística é o traço geográfico mais marcante e impressionante da Lousã e do seu contexto regional. Neste quadro de profundos contrastes, o relevo impõe-se como traço inconfundível e marca perene da nossa geografia (Figura 3). Como a região, desenhada entre o litoral e o interior, entre as terras baixas e de pequena altitude, e os relevos imponentes que anunciam a presença de serras e montanhas, alinhadas em escadaria, a Lousã reflecte a obra ciclópica das forças da natureza e o esforço antrópico materializado na sua organização espacial.
A Lousã é parte de um quadro regional e sub-regional heterogéneo, constituído por quatro unidades morfoestruturais diferenciadas que marcam de forma muito vigorosa a paisagem: o Maciço Antigo (com dois blocos principais de grandes elevações: Lousã-Açor-Estrela, e Muradal-Alvelos-Gardunha); a Bacia Sedimentar de Miranda do Corvo-Lousã-Góis-Arganil - no seu interior e bordadura encontram-se diversas formas de relevo, como, por exemplo, a bacia topográfica da Lousã (onde se desenvolve a vila homónima), as colinas sedimentares (Areal e Alto do Padrão), os terraços fluviais (Cume e Chã do Freixo), a Serra de Sacões (com os seus depósitos grosseiros de material heterométrico, de natureza estrutural e litológica diferente da Serra da Lousã) e o canhão fluvial da Senhora da Candosa (rasgado pelo rio Ceira no alinhamento quartzítico do Buçaco aos Penedos de Góis); o Rebordo Montanhoso do Maciço Antigo (com o Senhor da Serra e a Serra do Carvalho, entre outras), muito evidente entre Foz de Arouce e Coimbra; a Depressão Periférica (entre o Rebordo Montanhoso do Maciço Antigo e a Orla Mesocenozóica Ocidental), evidente, por exemplo, entre Penela e Coimbra, em particular ao longo das atuais estradas nacionais 342 e 110 , no percurso Lamas-Marco dos Pereiros.

A esta diversidade estrutural corresponde uma marcada heterogeneidade litológica (xistos, granitos,

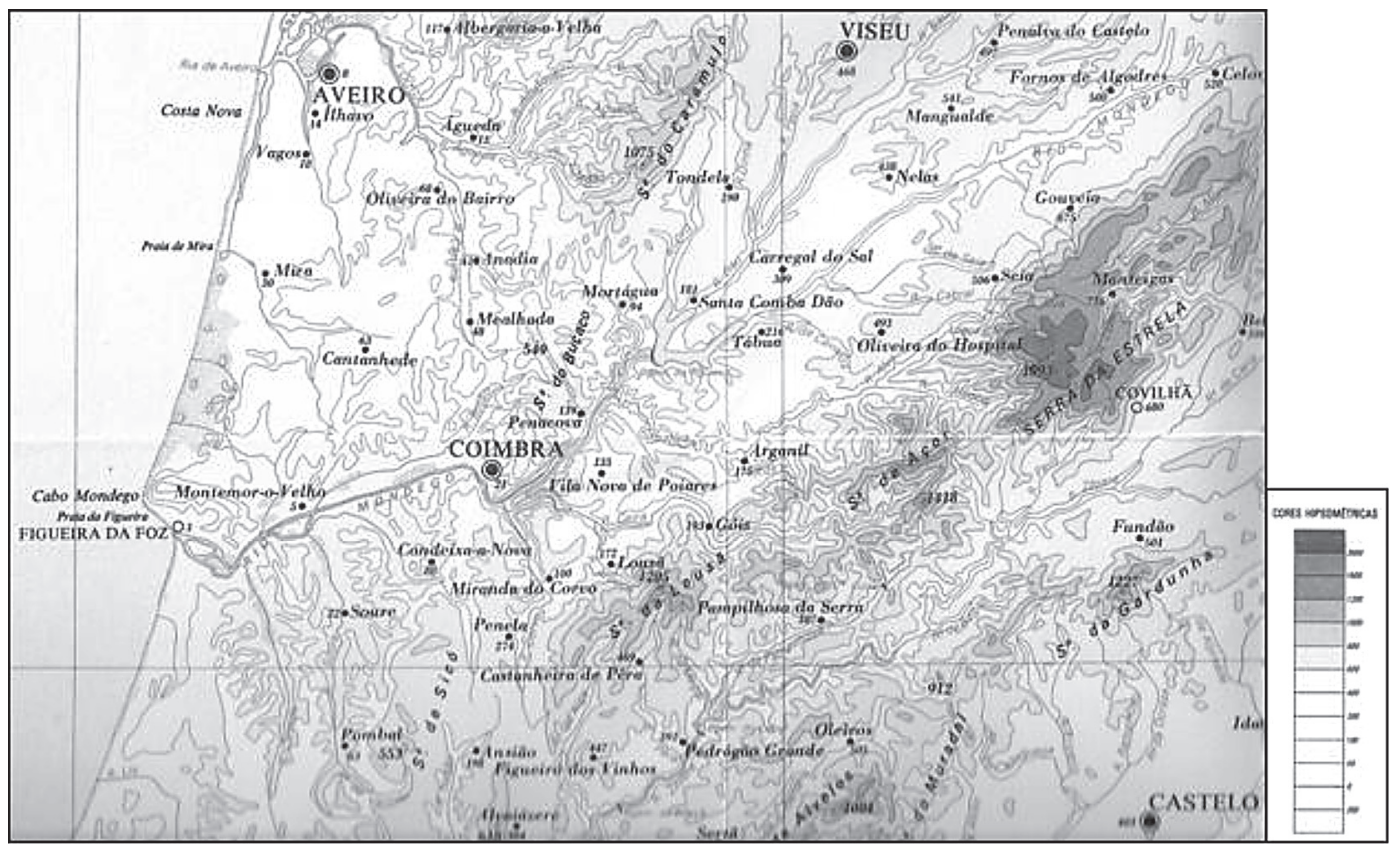

Figura 3

Mapa hipsométrico e de localização da Lousã

Fonte: Carta Hipsométrica de Portugal (1. 600 000; IGC, 1982) 
quartzitos, areias, arenitos, argilas, entre os mais importantes).

Esta contextualização é relevante para explicar as comunicações de e para a Lousã no início do século XIX.

\section{Vias de Comunicação}

O cenário geográfico traçado e o reconhecimento da influência negativa dos acidentes orográficos no que concerne ao traçado das vias e a sua penetração no interior do País, são argumentos de peso para afirmar que pelo menos até meados de Oitocentos a Lousã estava muito isolada e mal servida de vias de comunicação (Figura 4). Por um lado, o número (escasso), o traçado (irregular e muito difícil) e o estado de conservação das vias (péssimo), por outro, os meios de transporte (pedestre e tracção animal), dificultavam muito as deslocações de pessoas e bens, em especial nos espaços mais acidentados.

No período em análise, a matriz das comunicações é constituída pelas seguintes vias (de maior importância):
- A Estrada de Lisboa a Almeida (intitulada "real e militar"); esta via atravessava as colinas sedimentares a ocidente da Vila da Lousã; passava no Corvo, Padrão, Arneiro, Senhora do Desterro (Espinheiro), Foz de Arouce, Poiares e daí avançava para a Beira Alta. Em Foz de Arouce a grande referência espacial é o Rocio (próximo da ponte sobre o Rio Arouce). Figuras relevantes da investigação (estudiosos) da história local, como Álvaro Viana de Lemos e Belisário PIMENTA, em diversos trabalhos publicados, não deixaram de assinalar a importância desta via no contexto da Terceira Invasão Francesa, designadamente o episódio relacionado com a retirada de Massena e o Combate de Foz de Arouce (15 de março de 1811).

A Estrada Coimbra-Guarda, antecessora da moderna Estrada da Beira; o percurso antigo, entre o Mondego e o Alva, ou seja entre Coimbra e São Martinho da Cortiça, fazia-se pelas cumeadas da Serra do Carvalho (Rebordo Montanhoso do Maciço Antigo).

- A Estrada Coimbrã; esta via de comunicação partia do Fundo de Vila, atravessava a bacia da

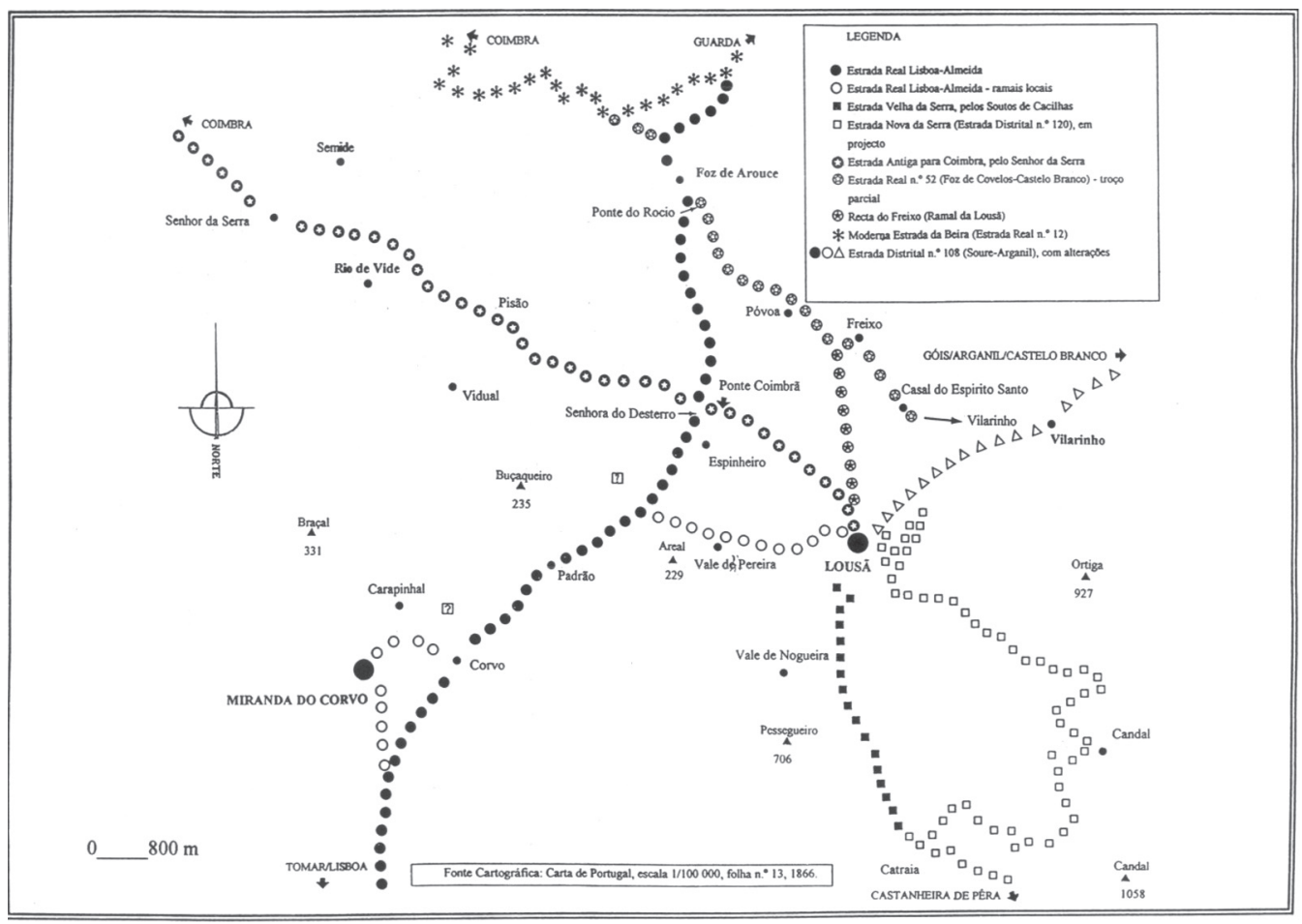

Figura 4

Esboço do quadro viário da Lousã no século XIX

Fonte: CARVALHo (1999:157) 
Lousã (Fonte dos Mouros, Senhora das Barraquinhas, Fontaínhas) e o Rio Arouce (Ponte Coimbrã), cruzava a Estrada Real Lisboa-Almeida na área da Senhora do Desterro, e seguia em direcção ao Senhor da Serra, de onde descia para Coimbra. Não era nada fácil a ligação entre Lousã e Coimbra.

A Estrada Velha da Serra, pelos Soutos de Cacilhas em direcção à Catraia, Coentrais, Castanheira de Pêra e Pedrógão Grande; foi este caminho, com traçado e condições de circulação muito difíceis, a plataforma de ligação entre os sectores setentrional e meridional da Serra da Lousã, e foi por ele que passou parte significativa da maquinaria que permitiu a modernização industrial de Castanheira de Pêra, na segunda metade do século XIX.

Esta estrutura viária principal estava articulada e complementada com eixos de escala ou importância local como, por exemplo, o Quelhão de Alfocheira (através de Gevim), a Quelha da Vaqueira (que conduzia à Favariça, Fiscal e Vilarinho), a Estrada da Fábrica (Cruz de Ferro-Penedo), a Estrada de Ceira (para o Freixo, Ceira dos Vales e Casal de Ermio).

Só na segunda metade do século XIX (a partir de 1860) e no início do século XX, o município da Lousã vai assistir a uma lenta mas marcante renovação das suas vias de comunicação. O novo mapa viário regional e local (Figura 4) inclui a Estrada Real n 12 (CoimbraCelorico da Beira), a Estrada Real $n^{\circ} 52$ (de Coimbra a Castelo Branco, ou melhor, da Foz de Covelos a Castelo Branco, uma vez que o traçado de Coimbra até à Foz de Covelos coincide com a Estrada Real $n^{\circ} 12$ ), a Estrada Distrital $n^{\circ} 66$ (Estrada Nova da Serra - Lousã-Castanheira de Pêra-Pedrógão Grande), a Estrada Distrital $n^{\circ} 57$ (Soure-Condeixa-Miranda do Corvo-Lousã-GóisArganil-Tábua) e o caminho de ferro de Coimbra até Arganil (apenas concretizado até ao termo oriental do município da Lousã). É importante sublinhar que as novas vias cruzaram a Vila e induziram novas direcções para o crescimento e consolidação da malha urbana (CARvalho, 1999). Posso mesmo dizer que este quadro viário, com melhorias pontuais e o lançamento das vias municipais, marcou o próprio século $X X$, pois apenas no final dos anos 90 teve início uma nova fase, com as variantes às estradas nacionais (342 e 236), concretizada na década seguinte, e ainda projectos e/ou realizações incontornáveis como uma nova ligação a Coimbra e a modernização/requalificação da Linha da Lousã.

\section{População e Povoamento}

Embora reconhecendo os problemas metodológicos e as limitações das fontes para o estudo da população e do povoamento em Portugal no período pré-censitário (anterior a 1864), de acordo com o "Censo de Pina Manique" (1798) e o "Censo do Conde de Linhares" (1801), a população do concelho da Lousã (ainda com a freguesia de Rio de Vide, mas sem Serpins, que era um município autónomo), na transição de Setecentos para Oitocentos, pode cifrar-se entre 6500 e 7000 habitantes (e na mesma avaliação, a população do reino pode estimar-se entre 3 e 3,5 milhões habitantes).

Como refere Joaquim Veríssimo SerRão (1970), a respeito da população em Portugal em 1798, a contagem dos habitantes do reino, por ordem de Diogo Inácio de Pina Manique (Intendente Geral da Polícia de Lisboa), teve uma finalidade imediata, de interesse militar, no recrutamento de tropas para a defesa de Portugal. Contudo, a principal dificuldade reside em encontrar o coeficiente exacto para obter a necessária avaliação do número de habitantes, a partir da variável (fogos) utilizada neste arrolamento.

Se admitirmos o multiplicador 4 (habitantes) para a unidade de referência (fogos) do Censo de Pina Manique, a população da Lousã em 1798, por freguesia, seria do seguinte modo: Casal de Ermio (225), Foz de Arouce (1032), Lousã (3644), Rio de Vide (852) e Vilarinho (1300). 0 município de Serpins teria cerca de 1700 habitantes. Outras publicações, relacionadas com autores estrangeiros (como José CoRNIDE e Adrien BALBI), apresentam valores semelhantes para o mesmo período.

Por sua vez, as "Taboas Topograficas e Estatisticas" (Figura 5) é uma nova contagem dos fogos e almas de todas as Comarcas de Portugal, elaborada em 1801, por ordem de D. Rodrigo de Sousa Coutinho (Conde de Linhares). A Lousã e o seu termo tinham quatro freguesias, 1777 fogos e 6511 almas (das quais 3138, ou seja 48\%, na freguesia da Lousã). O quadro demográfico apresentava a seguinte distribuição geográfica regional: Coimbra (46958 almas, das quais 15210 residiam na $\mathrm{Ci}$ dade); Montemor-o-Velho (10981); Cantanhede (10210); Figueira (9761); Penacova (8561); Arganil (7391); Penela (7364); Pedrógão Grande (6688); Miranda do Corvo (6413); Góis (4881); Alvaiázere (3420); Pampilhosa (3416); Pombeiro (3076); Maiorca (2526); Figueiró (2410); Álvares (2157); Semide (1827); Cernache (1636); Serpins (1641); Ancião (1472); Tentúgal (1539); Buarcos (1385); Carvalho (997); Podentes (673), e Fajão (317). É evidente a maior expressão demográfica das terras do Baixo Mondego, embora a relação com o Pinhal Interior 
estivesse longe das assimetrias atuais (movimento que se acentua na primeira metade do século $X X$ e, ainda com mais intensidade, nas últimas décadas).

Os registos demográficos do início do século XIX comprovam o acréscimo da população do reino desde o início do século XVI, apesar das diversas oscilações documentadas no referido período. De acordo com o Numeramento ou Cadastro da População do Reino, a fonte mais antiga para a reconstituição da população e do povoamento em Portugal, que na Comarca da Beira foi realizado em 1527, a Vila da Lousã e seu Termo apresentavam 525 moradores (cerca de 2100 habitantes). Uma tentativa de tradução da população por freguesias, permite admitir o seguinte cenário: Foz de Arouce (340 habitantes), Lousã (1064), Rio de Vide (152) e Vilarinho (548).

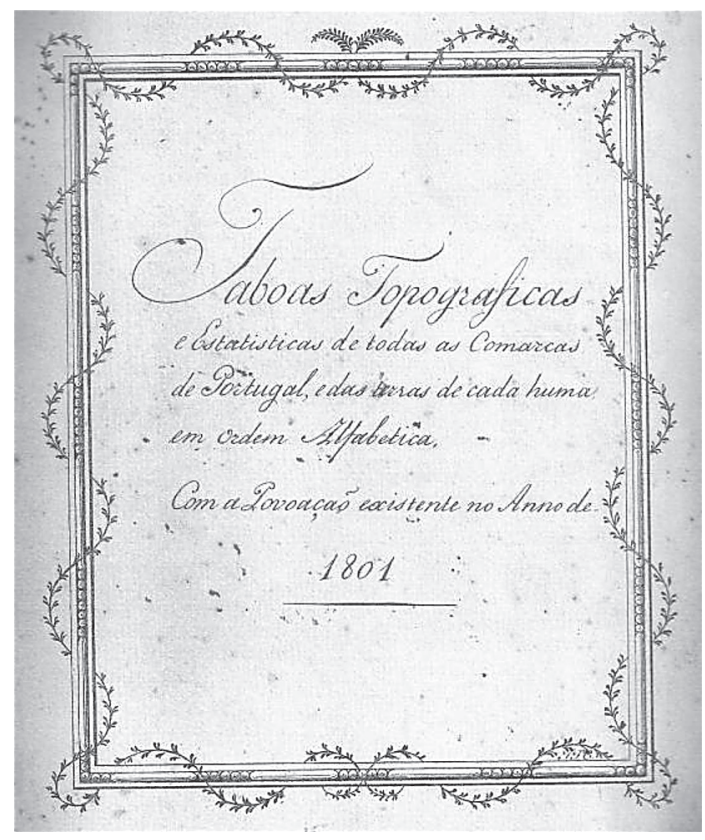

Figura 5

Folha de rosto das "Taboas Topograficas e Estatisticas (1801) - manuscrito reproduzido pelo Instituto Nacional de Estatística em 1948 Fonte: INE (1948)

Ainda em Oitocentos, importa referir os resultados do primeiro Recenseamento Geral da População (de acordo com as orientações do Congresso Internacional de Estatística - Bruxelas, 1853), que decorreu em Portugal no ano de 1864, para se perceber o sentido da evolução demográfica. A população presente no concelho da Lousã foi contabilizada em 9577 habitantes, repartida pelas freguesias do seguinte modo: Casal de Ermio (340), Foz de Arouce (1173), Lousã (4567, que equivale a $48 \%$ do total), Serpins (1748) e Vilarinho (1759). Dai em diante o facto mais relevante será o crescimento demográfico da freguesia da Lousã (que em 2001 representava $66 \%$ do total demográfico do concelho).

Por outro lado, considerando o quadro geográfico regional, é preciso afirmar que as assimetrias demográficas de hoje eram bem menos evidentes nesse período (como já referimos). No final do século XIX, a população dos municípios de Lousã, Miranda do Corvo, Góis, Pedrógão Grande e Figueiró dos Vinhos aparece repartida no intervalo de variação entre 10 e 15 mil habitantes. Esta relação alterou-se de modo significativo em particular na segunda metade do século XX. O interior serrano foi ainda mais marcado pelo despovoamento e envelhecimento. A título de exemplo (paradigmático), posso afirmar que as freguesias de Álvares (Góis), Coentral (Castanheira de Pêra), Campelo (Figueiró dos Vinhos) e Espinhal (Penela), no período 1911-2001, perderam mais de $70 \%$ da população residente (CARVALHO, 2005).

De acordo com os resultados preliminares dos Censos 2011, a população do concelho da Lousã (17606 habitantes) é superior (em número) ao conjunto da população dos municípios de Góis (4260), Castanheira de Pêra (3191), Figueiró dos Vinhos (6169) e Pedrógão Grande (3915) que perfaz 17535 habitantes - em 2001 esses valores eram de 15753 e 20344 habitantes, respectivamente. Significa uma variação decenal positiva de $11.8 \%$ para o município da Lousã, em sentido oposto ao da evolução da população residente de quase todos os municípios do Pinhal Interior (com decréscimo entre 4.2 e $16.1 \%$ ), o que aliás, com variações pontuais, reforça a tendência da evolução demográfica desenhada das últimas três décadas. No período 1981-2011, a variação da população residente (em \%) no Pinhal Interior Norte $(-14.1 \%)$ revela dois sentidos principais: o crescimento, moderado (Miranda do Corvo e Vila Nova de Poiares, com valores de 7.5 e $10.4 \%$, respetivamente) e elevado (Lousã, com 31.4\%); o decréscimo, moderado (Tábua, Oliveira do Hospital e Ansião, com -10.6, -11.9 e $-15.7 \%$, respetivamente), elevado (Arganil e Penela, -23.9 e $-27.8 \%$, respetivamente) e muito elevado (Figueiró dos Vinhos, -32.8\%; Alvaiázere, -34.4\%; Pedrógão Grande, -36.8\%; Góis, -38.4\%; Castanheira de Pêra, -44\%; Pampilhosa da Serra, -46.8\%). Contudo, para confirmar esta leitura, é preciso esperar pelos resultados definitivos do processo censitário em curso.

Por outro lado, importa analisar a estrutura e a evolução do povoamento. O cruzamento de diversas fontes (como, por exemplo, os registos paroquiais, as informações paroquiais, os apuramentos demográficos e militares, as primeiras estatísticas publicadas), per- 
mite afirmar que em 1527 estavam identificados cerca de $40 \%$ dos povoados existentes no município da Lousã até meados do século XIX, quando a matriz do povoamento atinge a máxima representatividade, no que diz respeito ao número de lugares (CARVALHO, 1999). Isto significa que dos 169 lugares povoados da Lousã (segundo a moderna configuração administrativa do século XIX), cerca de $60 \%$ aparecem entre 1528 e 1854 , do seguinte modo: $19 \%$, entre 1528 e 1687; 22\%, entre 1688 e 1758 , e 20\%, entre 1759 e 1854 (data de publicação do "Mapa do Distrito Administrativo de Coimbra”).

Assim, o período compreendido entre o início do século XVI e os meados de Oitocentos, reflecte profundas alterações ao nível da estrutura do povoamento em particular o aumento do número de pequenos lugares $e$ a sua grande dispersão geográfica, resultado da nova organização do espaço rural decorrente da difusão das espécies alimentares provenientes do Novo Mundo, como o milho grosso, o feijão, a abóbora e (embora mais tarde) a batata.

A Lousã viu aumentar o número de pequenos lugares sem que a sede de concelho tivesse registado dinâmica demográfica assinalável (CARVALHO, 1996; 1999). Em 1527 foram assinalados 161 moradores (cerca de 650 habitantes) na Vila da Lousã, ou seja 31\% do total apurado no concelho. Este valor estimativo sofreu alterações pouco significativas até ao final do século XIX. O "Mapa Estatístico do Distrito de Coimbra", publicado em 1885, dá conta de 582 habitantes na Vila da Lousã, e o "Censo da População de 1911" (o primeiro registo censitário moderno, por lugar), assinala 942 habitantes para a Vila da Lousã (valor que sobe para 1152, em 1940). Porém, a imagem da vila torna-se singular com a construção de importantes casas senhoriais relacionadas com a fidalguia rural, em particular no século XVIII (processo que marca também outros lugares do termo da Lousã, como Casal dos Rios, Fiscal e Foz de Arouce).

É esta a ponte para o derradeiro eixo da presente reflexão (a expressão geográfica da Vila da Lousã no início de Oitocentos).

\section{Espaço Urbano: a Vila da Lousã}

Como referimos em trabalhos anteriores, a Vila da Lousã, até ao último terço do século XIX (antes da renovação das vias de comunicação), era um espaço de pequenas dimensões (na perspetiva de indicadores como o espaço construído, a população e as atividades económicas).
O desenho urbano apresentava um eixo principal em forma alongada constituído pelas antigas ruas de Santo Cristo (atual rua do Comércio) e Direita (atual rua Viscondessa do Espinhal), a que se juntavam as ruas Nova, dos Ferreiros, da Fonte, de Palhais, de S. João, da Graça, e as estradas principais de entrada/saída da vila, na Fonte dos Mouros, Tapada do Fundo de Vila, Graça, Vaqueira, Travessa, Regueiro e Cimo de Vila Figura 6.

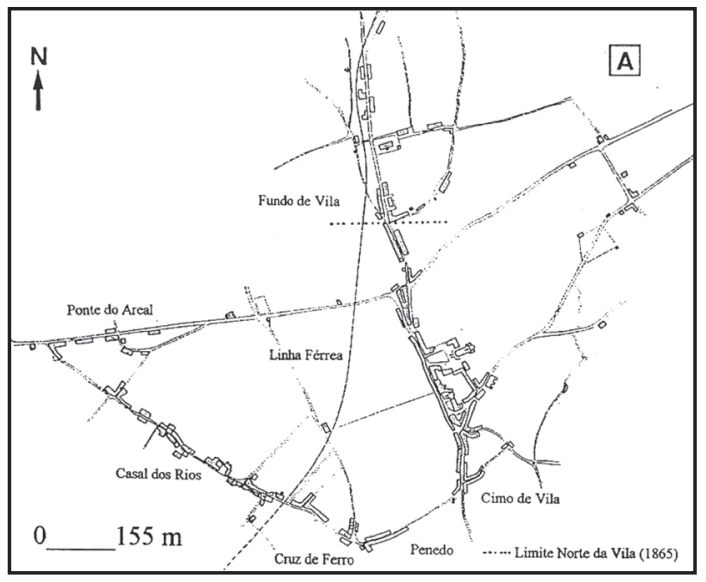

Figura 6

A Vila da Lousã na transição dos séculos XIX-XX Fonte: CARVALHo (1999: 293)

A malha urbana consolidada estendia-se, partindo do norte, entre as imediações da Casa do Fundo de Vila, Santo António (Cimo de Vila) e Fonte da Arcada, em jeito de limite meridional da vila geográfica, para além da qual ficavam os subúrbios da Cruz de Ferro, Ponte Quadiz e Penedo. Ao mesmo tempo, importa assinalar o eixo de povoamento ocidental da Lousã, constituído pelos lugares de Casal dos Rios, Porto da Reguenga e Ponte do Areal, entroncando o caminho que os ligava na estrada velha para Miranda do Corvo, onde também convergiam os dois antigos eixos viários de ligação aos lugares dos Cômoros-Moita-Olival e PapanataRibeira-Fontaínhas.

Portanto, o espaço urbano da Lousã no período das Invasões Francesas/Guerra Peninsular corresponde ao atual setor meridional do Centro Histórico (na versão do Plano Diretor Municipal de 1993, em que a parte setentrional decorre da evolução urbana no período dos anos 60 /século XIX até ao alvor do século XX), balizado pelos elementos urbanísticos referidos e considerando apenas as estruturas e os espaços coevos.

Em parte do reduto oitocentista, maioritariamente herdeiro da centúria precedente, estavam insta- 
lados os serviços administrativos públicos essenciais decorrentes da categoria do burgo, dispersando-se os restantes serviços particulares pela malha urbana, numa época em que o comércio, sem assumir ainda de forma generalizada o carácter fixo que seria difundido (ou pelo menos reforçado) localmente nos últimos lustros de Oitocentos, assentava principalmente na modalidade ambulante, assumindo particular expressão nas feiras que, sucedendo-se em cadência semanal, mensal e anual, animavam a velha e acanhada praça do município e as suas imediações, estendendo-se ao Regueiro, no caso da feira do gado.

Apesar da pequena expressão territorial e demográfica da vila, importa sublinhar o seu património construído, em especial os imóveis mais relevantes que aos séculos XVII, XVIII e XIX (primeiros tempos) devem a sua génese/consolidação.

Desse tempo, ainda marcam presença no tecido urbano da Lousã a Casa do Fundo de Vila ou do CapitãoMor (Quinta das Courelas), a Casa de Baixo da Rua Nova, a Casa de Cima da Rua Nova, a Igreja da Misericórdia (que conserva no portal a data de 1568), os Antigos Paços do Concelho (edifício que sofreu diversas reconstruções e ampliações nos séculos XVIII e XIX) e o Palácio Salazar. Este último, mandado edificar no início de Oitocentos (a data de 1818 está gravada no portal) pelo pai da Viscondessa do Espinhal (D. Maria da Piedade Salazar), "substituiu velhas construções no mesmo local, por certo pertencentes à mesma família que há muito já vivia na Lousã (Lemos, 1951: 69). A casa da família Salazar serviu para instalar o quartel general do exército anglo-luso e de onde Wellesley "(...) expediu correspondência oficial datada de 16 de março de 1811" (LEmos, 1951: 56). Na atualidade, o Palácio Salazar é um

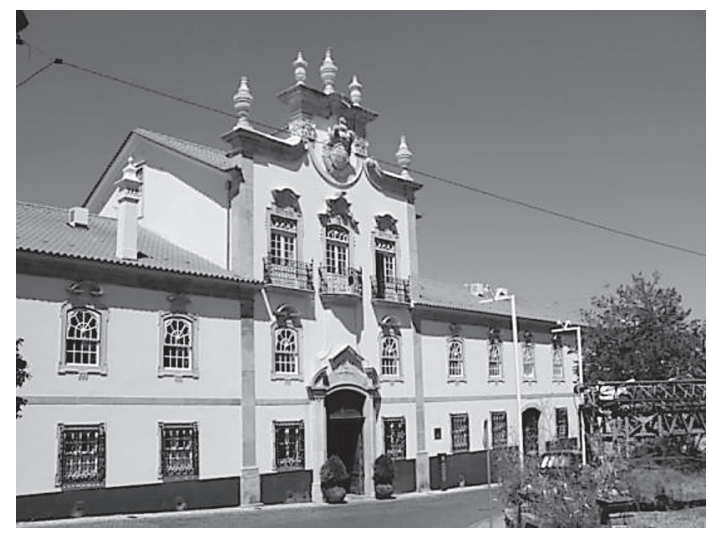

Figura 7

Melia Palácio da Lousã (após as obras de recuperação da antiga casa de família da Viscondessa do Espinhal) - junho de 2009 hotel de charme (Melia Palácio da Lousã - Figura 7), depois de ter sofrido importantes obras de requalificação e ampliação.

Entretanto perdido para todo o sempre está o Solar Costa Mesquita (a parte central, a última que chegou até aos nosso dias, foi demolida nos anos $70 /$ século $X X)$, a Casa dos Feios de Carvalho (igualmente demolida nos anos 70/século XX, para alargamento da praça do município) e as Casas da Rua da Fonte (das famílias Monteiros de Távora, Ferraz e Sacadura, que foram demolidas nos anos 20/século XX para alargamento e retificação do respetivo arruamento), todas na parte central da Vila antiga, entre outras construções igualmente desaparecidas (como, por exemplo, a antiga Igreja Paroquial, demolida em 1873, para dar lugar à nova Igreja Matriz).

O termo da Lousã acompanha este conjunto notável, com importantes casas solarengas (do tipo do século XVIII, por vezes acompanhadas de elegantes capelas particulares) em Casal dos Rios (Casa dos Magalhães Mexia/ Quinta de Santa Rita), Fiscal (Casa dos Lopes Quaresma e Casa dos Magalhães Mexia/Casa do Arco) e Foz de Arouce (Casa dos Condes de Foz de Arouce - Figura 8). Como nota Álvaro Viana de Lemos (1951: 71), "(...) algum papel deve ter desempenhado este edifício por ocasião do combate da ponte de Foz de Arouce".

É preciso esperar pela segunda metade do século XIX para encontrar sinais incontornáveis do crescimento e qualificação do espaço urbano, como demonstram os seguintes exemplos: construção do Teatro (1859); construção da Escola Primária (inaugurada em 1868); construção do Hospital de São João (no Olival da Serra), com início em 1866; reforma/ampliação do edifício dos Antigos Paços do Concelho (1861), construção da Nova Igreja Matriz (com demolição da anterior, entre 1874 e

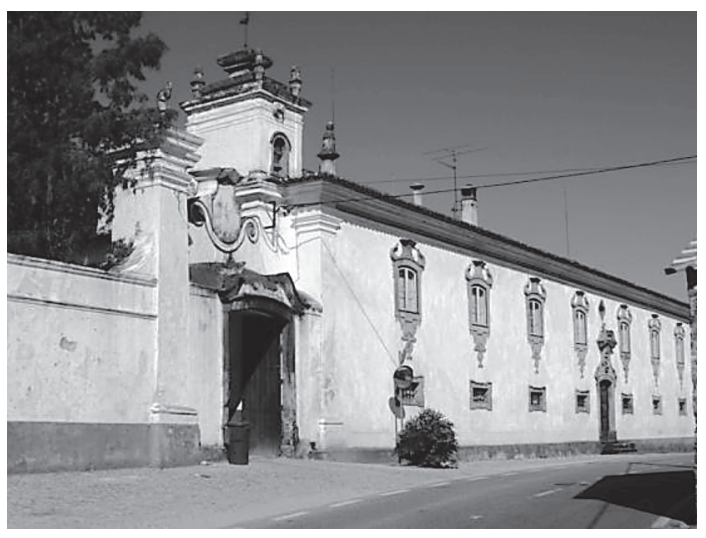

Figura 8

Casa dos Condes de Foz de Arouce (junho de 2009) 


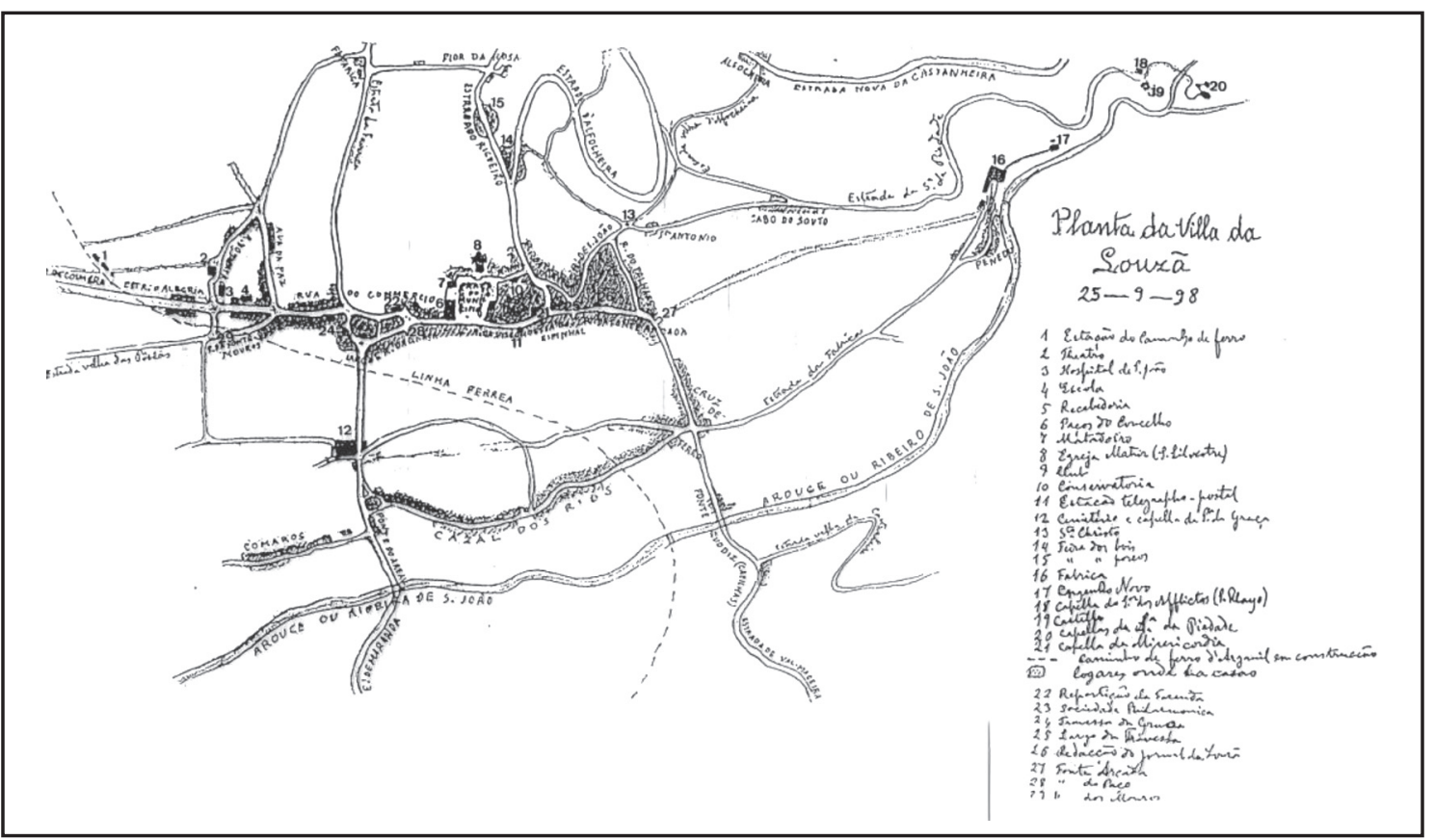

Figura 9

Planta da Vila da Lousã (1898), desenhada por Álvaro Viana de Lemos

Fonte: CarValHo (1999: 216).

1882) e reconfiguração (com alargamento) da Praça do Município, quase em simultâneo com as obras relacionadas com a estrada distrital Soure-Arganil (que atravessou a vila), naquilo a que podemos considerar a primeira operação de renovação urbana da Lousã; iluminação pública (1886), abastecimento de água, com a construção de fontenários no Regueiro (1886/87), Praça do Município (1888) e Sarnadinha (1891), e a pavimentação dos arruamentos urbanos.

A planta da Vila da Lousã em 1898 (Figura 9), desenhada por Álvaro Viana de Lemos, permite perceber a expressão urbana da Lousã no final de Oitocentos, quase um século após a Terceira Invasão Francesa e o Combate de Foz e Arouce (março de 1811).

\section{Referências Bibliográficas}

ALEgrIA, M. F. (1990) - A organização dos transportes em Portugal (1850-1910). As vias e o tráfego, Memórias do C.E.G. $n^{\circ}$ 12. Lisboa, Universidade de Lisboa/INIC, $560 \mathrm{p}$.

AndRAde, A. R. (1885) - Mapa estatístico do distrito de Coimbra. Coimbra, Imprensa da Universidade, pp. 63-68.

ANDRADE, A. R. (1896) - Corografia histórico-estatística do distrito de Coimbra. Coimbra, Imprensa da Universidade, pp 7-13; 106-111.
BALBI, A. (1822) - Essai statistique sur le Royaume du Portugal e d'Algarve, comparé aux outres états de l'Europe, et suivi d'un coupe d'oeil sur l'état actuel des Sciences, des Lèthres et des Beaux-arts parmi les Portugais des deux Hémisféres. Paris, Chez Rey et Garnier Libraires, vol. I, pp. 66-75; 186-205; vol. II, pp 162-167; 201-205

BAPTISTA, M. D. (1798) - "Ensaio de uma descrição física e económica de Coimbra e seus arredores". Memórias Económicas da Academia Real das Ciências de Lisboa. Lisboa, tomo I, pp. 254-298.

CARDOSO, L. (1747) - Dicionário geográfico ou notícia histórica de todas as cidades, vilas e lugares (...). Lisboa, tomo I, pp. 366-36.

CARDOSO, L. (1751) - Dicionário geográfico ou notícia histórica de todas as cidades, vilas e lugares (...). Lisboa, tomo II, pp. 153; 353; 410; 532; 568; 576; 637.

Carvalho, P. (1999) - A Vila da Lousã. Contributo para um estudo de Geografia Urbana. Lousã, Câmara Municipal da Lousã, $457 \mathrm{p}$.

Carvalho, P. (2009) - Património construído e trajectórias de desenvolvimento em áreas de montanha. O exemplo da Serra da Lousã. Lousã, Câmara Municipal da Lousã, $657 \mathrm{p}$.

CASTRo, J. B. de (1762) - Mapa de Portugal Antigo e Moderno. Lisboa, Oficina Patriarcal de Fernando Ameno, tomo I, pp. $45 ; 59-67$. 
Chorão, M. J. M. B. (1987) - "Inquéritos promovidos pela Coroa no século XVIII". Revista de História Económica e Social, n. ${ }^{\circ} 21$, Set./Dez., pp. 93-130.

CHORÃo, M. J. M. B. (1988) - "Inventário da Lousã nos meados do século XVIII". Jornadas de Cultura e Turismo (16-17 de Julho de 1988), Lousã, B.M.L/C.M.L., pp. 131-153.

Colaço, J. T. de M. (1934) - "Cadastro da População do Reino (1527). Actas das Comarcas dantre Tejo e Odiana e da Beira". Revista da Faculdade de Direito da Universidade de Lisboa, Lisboa, Ano II, pp. 28-243.

DaveAu, S. et col. (1985-86) - Les bassins de Lousã et d'Arganil. Recherches géomorphologiques et sédimentológiques sur le Massif Ancien et sa couverture à l'Est de Coimbra (vol. 1-Le bassin sédimentaire, vol. 2-L'évolution du relief), Col. Memórias do Centro de Estudos Geográficos $\mathrm{n}^{\circ}$ 8, Lisboa, Centro de Estudos Geográficos.

DaVEAU, S. (1988) - "Contribuição para uma colectânea de antigas descrições geográficas da Lousã". Jornadas de Turismo e Cultura, Lousã, B.M.L/C.M.L., pp. 88-111.

Dias, P. e Rebelo, F. (1985) - Lousã. A Terra e as Gentes, Lousã, Edição da C.M.L., 95 p.

Freire, A. B. (1908) - "Povoação da Estremadura no XVI". Arquivo Histórico Português, vol. 6 (7), pp. 241-284.

Galego, J. e Daveau, S. (1986) - o Numeramento de 1527-1532. Tratamento Cartográfico, Lisboa, Centro de Estudos Geográficos.

Girão, A. de A. e Velho, F. L. (1954) - "O mais antigo censo da população de Portugal (1527)". Boletim do Centro de Estudos Geográficos, Coimbra, n. ${ }^{\text {os }} 8-9$, pp. 58-68.

INE (1948) - "Tábuas Topográficas e Estatísticas - 1801", Subsídios para a História da Estatística em Portugal, vol. II, Lisboa, Instituto Nacional de Estatística.

Leão, D. N. de (1785) - Descrição do Reino de Portugal. Lisboa, Oficina de Simão Tadeu Ferreira, $2^{a}$ edição, pp. 12; 80 $81 ; 119$.
Lemos, Á. V. de (1951) - A Lousã e o seu Concelho. Coimbra, Imprensa de Coimbra, $170 \mathrm{p}$.

Mаввот, G. B. de (1891) - Memóire du Général Baron de Marbot,

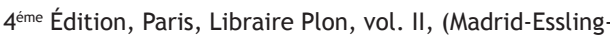
Torres Vedras), pp. 436-447.

Matos, A. T. de (1980) - Transportes e Comunicações em Portugal, Açores e Madeira (1750-1850). Ponta Delgada, $650 \mathrm{p}$.

NizA, P. D. de (1757) - Portugal sacro-profano ou catálogo alfabético de todas as freguesias do Reino de Portugal e Algarves, das igrejas e dos seus oragos. Lisboa, Oficina de Miguel da Costa, Parte I, pp. 252; 337.

NizA, P. D. de (1768) - Portugal sacro-profano ou catálogo alfabético de todas as freguesias do Reino de Portugal e Algarves, das igrejas e dos seus oragos. Lisboa, Oficina de Miguel da Costa, Parte II, pp. 180; 326; 380; 396.

Paiva, J. e Carvalho, J. (1989) - "A diocese de Coimbra no século XVIII. População, oragos, padroados e títulos dos párocos". Revista de História e Teoria das Ideias, Coimbra, vol. XI, pp. 175-268.

Pimenta, B. (1958) - "Velharias - Invasões Francesas: recontro de Foz de Arouce”. O Povo da Lousã, n 1183, 15/02/1958, p. 4.

SEco, A. L. H. (1853) - Memória histórico-corográfica dos diversos concelhos do distrito administrativo de Coimbra. Coimbra, Imprensa da Universidade, pp. 7276.

SeCo, A. L. H. (1854) - Mapa do distrito administrativo de Coimbra. Coimbra, Imprensa da Universidade, pp. 57 61; 96-99.

Serrão, J. V. (1970) - A população de Portugal em 1798. O Censo de Pina Manique, Fontes Documentais Portuguesas I. Paris, Centro Cultural Português, Fundação Calouste Gulbenkian, pp. XII-XXX. 